\title{
EMPRESAS E DIREITOS HUMANOS: ENTRE O LUCRO E A ÉTICA
}

\section{CORPORATIONS AND HUMAN RIGHTS: BETWEEN ETHICS AND PROFIT}

\author{
${ }^{1}$ Annuska Macedo Santos de França Paiva
}

\section{RESUMO}

Através de pesquisa bibliográfica dedutiva, pondera-se que a centralidade das empresas nas discussões internacionais sobre direitos humanos obnubila que, para o efetivo cumprimento da função social corporativa, é necessário que as empresas não apenas respeitem, mas os promovam, através de medidas conjuntas dos Estados e sociedade civil. A excessiva voluntariedade dada às ações empresariais faz com que tal promoção - geralmente via responsabilidade social corporativa - seja definida por critérios utilitaristas. Porém, temperadas com a função social da propriedade, tais ações são de efetiva responsabilidade empresarial, exigíveis pelos Estados e sociedade civil, através de regulação e processos de accountability corporativa.

Palavras-chave: Responsabilidade Social Corporativa; Função social da propriedade; Direitos Humanos e empresas; Nova ética empresarial; Regulação estatal

\begin{abstract}
Corporations shall be faced as a means to society, due to their social role - which is a requisite to the property rights in Brazilian legal system. Using a bibiographical research and deductive approach, the corporation's centrality on international Human Rights discussions hinders that companies shall not only respect, but promote human rights due to the corporation social role. For that, cooperative programs with Governments and society are necessary. The excess of voluntarism on corporate social responsability makes it a prisioner of utilitarism, pointing the need to change towards corporate accountability and hard regulation to the realization of human rights.
\end{abstract}

Keywords: Corporate Social Responsibility; Social Role of Property; Corporations and human rights; New business ethics; Regulation

\footnotetext{
${ }^{1}$ Doutoranda em Direitos Humanos e Desenvolvimento pela Universidade Federal da Paraíba (UFPB), João Pessoa, Paraíba, Brasil. Direção e administração pelo Instituto Federal de Educação, Ciência e Tecnologia da Paraíba (IFPB), Sousa, Paraíba, Brasil. Email: tutortreinamento@gmail.com
} 


\section{INTRODUÇÃO}

O debate acerca das relações entre mercado e política tradicionalmente baseia-se em modelos que consideram as agências estatais como únicas instituições políticas que diretamente influenciam no bem-estar da sociedade, sendo às empresas relegado apenas o papel de atores econômicos. O aprofundamento da globalização, no entanto, enevoa a antes clara separação entre as esferas políticas e econômicas: a perda da homogeneidade cultural decorrente do pluralismo da sociedade moderna e as relações transnacionais erodiram ainda mais o contexto nacionalizado de governança. Em muitos casos, o sistema estatal falha em regular a economia, em lidar com questões socioambientais globais, em possibilitar a cidadania transfronteiriça e em servir o interesse público em geral. Assim, grupos da sociedade civil organizada e multinacionais tendem a participar da formulação e implementação das políticas públicas nas mais diversas áreas: proteção dos direitos humanos, preservação ambiental e lutas contra a corrupção estão incluídos.

Por esta razão, as empresas passam a ser vistas como atores econômicos e políticos da sociedade. No entanto, a sua motivação em assumir este papel não é cristalina. Ao mesmo tempo em que participam de discussões internacionais sobre ética corporativa, as empresas se mostram difíceis de responsabilização por violações correntes de direitos fundamentais, tanto de seus empregados como das comunidades afetadas por suas atividades. Assim, pergunta-se: qual relação pode ser estabelecida entre empresas e direitos humanos? Indicamos duas hipóteses para a observância desses direitos pelas corporações: a primeira corrente indica que seu respeito decorre de anseios éticos decorrentes da evolução do mercado; a segunda possibilidade é que tal vinculação é determinada por utilitarismo econômico. Para responder tal problema, utilizar-se-á de referências bibliográfico-normativas, analisadas dedutivamente. $\mathrm{O}$ artigo se divide em três seções:

Inicialmente, é realizada uma análise teleológica das empresas. Através da discussão entre fins e meios, baseada mormente em Benjamin e Kant, será estabelecida a relação entre propriedade e empresa, para analisar as suas funções. Apresentadas as principais correntes internacionais sobre o assunto, busca-se indicar quais diferenças na finalidade da empresa são possibilitadas pelo ordenamento jurídico brasileiro.

Em um segundo momento, tratar-se-á sobre a relação entre empresas e direitos humanos estabelecidas por discussões internacionais. Em vez de focar na ausência de subjetividade das corporações no direito internacional, ou destacar a ausência de remédios 
transnacionais para os abusos em direitos humanos cometidos pelas empresas, discute-se direitos humanos e corporações. Para tanto, analisar-se-á como o descritivismo e o prescritivismo interagem com o Direito, tomando por base Kelsen, Hare e Austin.

Finalmente, utilizando categorias de Douzinas e Debord, indicar-se-á possíveis motivações para práticas de responsabilidade social corporativa e os seus potenciais impactos para realizar as mudanças estruturais necessárias ao desenvolvimento. $\mathrm{O}$ fio condutor de toda a análise serão os direitos humanos e a sua necessária efetivação na sociedade.

\section{A finalidade das empresas: entre o lucro e a responsabilidade social}

Com a concentração empresarial promovida pelas grandes companhias, os acionistas saíram do eixo de controle sobre a gestão organizacional da empresa. A dispersão do capital social entre vários acionistas e a possibilidade de livre transferência das ações resultaram em uma lacuna entre a propriedade da sociedade anônima e a sua gestão, o que gerou a divergência de interesses conhecida por conflito de agência. Neste, o principal - titular da propriedade - delega ao agente - gerente da propriedade - a capacidade para agir em seu nome e defender seus interesses. Tal dissociação entre a propriedade acionária e a gerência das empresas é recorrente na literatura estadunidense sob a denominação de agency relationship e fundamentou a instituição de várias normas - legais ou contratuais - para eliminar ou, ao menos, diminuir, tal divergência tornou-se fundamento para a instituição de diversas normas - legais ou contratuais - que visam a eliminar ou, ao menos, diminuir esse desacordo de interesses.

Esta separação gerencial fez com que a empresa seja vista como mera propriedade pelos acionistas. Assim, a atividade empresarial seria meio para as finalidades de seus acionistas. Tal fim, no entanto, não é unívoco, pela falta de homogeneidade nessa categoria. Por outro lado, a atividade empresarial se organiza através de uma entidade juridicamente distinta: o Direito cria a ficção da pessoa jurídica para possibilitar o destacamento patrimonial para a atividade econômica, dando-lhe tratamento diferenciado tanto em questões públicas como a tributação - quanto privadas - como a responsabilidade cível e penal da empresa, a qual é de modo frequente, independente e distinta da de seus acionistas. Assim, para o melhor entendimento da empresa e de suas obrigações, é necessário entrar em discussão teleológica sobre o seu papel. A discussão entre meios e fins divide os militantes em Direitos Humanos. No entanto, essa não é uma relação linear nem causal: seu aprofundado conteúdo ético 
confere-lhe caráter deontológico.

Em um sistema legal, a relação entre meios e fins é essencial: se a violência não é um objetivo ético nem político, ela deve estar adstrita à esfera dos meios - como uma força efetiva, que sanciona a violência seja qual for sua justificativa ou legitimação. O dogma básico de qualquer teoria de violência será, portanto “os fins justos podem ser alcançados por meios legítimos, e os meios legítimos, aplicados para alcançar fins justos” (BENJAMIN, 2013, p. 60). Benjamin menciona duas tradições jurídicas que legitimam a violência de forma diametralmente oposta: o jusnaturalismo e o positivismo. Enquanto aquela considera que o uso de meios violentos para fins justos é uma questão equivalente a um homem considerar ser seu direito direcionar seu corpo para certo objetivo, esta, a escola do direito positivo, está mais preocupada com a ideia de fins justos. "Se o direito natural pode julgar qualquer direito existente apenas criticando seus fins, então o Direito positivo poderá julgar todo o Direito em evolução apenas através da crítica dos seus meios.” (BENJAMIN, 2013, p. 60). Benjamin não se filia a qualquer das duas correntes, apesar de reconhecer os esforços da escola positivista em focar na justificar dos meios, enquanto o jusnaturalismo retrata a violência como um produto quase-orgânico da natureza, como se o agir violento fosse um material cru. No entanto, ambas as correntes incorrem no mesmo deslize: ao falar em violência, acreditam em um nexo instrumental entre meios e fins. O direito natural visa a, pela justiça dos fins, justificar os meios; o direito positivo, à justeza dos fins pela justificação dos meios. Em contraste, Benjamin nega qualquer crítica da violência baseada na discussão de meios e fins, pois "se a justiça é o critério dos fins, a legitimidade é o critério dos meios" (BENJAMIN, 2013, p. 60)

Essa negativa não é apenas teórica, mas de grande importaria política. enquanto a posição jusnaturalista é frequentemente utilizada para legitimar lutas armadas antiOhegemônicas, anti-estatais ou anticoloniais, a corrente oposta, positivista, é utilizada pelo estado para justificar a coerção institucionalizada ou a repressão estatal. Apesar de as teorias serem diametralmente opostas quanto a ênfase em meios ou fins justos, ambas comungam da ideia de que a violência pode ser entendida em uma relação causal. Benjamin, por sua vez, insiste em critérios independentes para meios legítimos e fins justos.

Seguindo essa argumentação, até o mais básico princípio teológico do Decálogo Não matarás -, não pode ser entendido como um meio proibido em relação a um fím justo ou injusto. O fato em si, o meio "matar" deve ser analisado como tal, sem referir-se a um possível objetivo. Assim, nenhum julgamento do ato pode ser decorrente da sua inspiração: 
esta não existe como um critério de julgamento, mas como recomendação para as ações das pessoas ou comunidades. Tais instruções de ações, no entanto, nunca são totalmente aplicadas para as situações, pois apenas prescrevem orientações gerais. Discussões sobre como e se uma situação concreta pode ser guiada por um princípio ético são corriqueiras. E é justamente sobre esse trabalho infinito e inatingível de negociação que surge desta ausência de critério absoluto que Kant trata em sua Fundamentação à Metafísica dos Costumes. De acordo com a primeira formula kantiana de imperativo categórico, deve-se "agir apenas segundo a máxima que possas desejar que se torne lei universal” (KANT, 2003, p. 104, tradução nossa). Sendo este imperativo um autossuficiente fim em si mesmo, ou fim puro - em vez de meio para outro fim -, deve manter uma aplicabilidade universal e perene para todas as possíveis situações históricas. No entanto, Benjamin se opõe fortemente ao esvaziamento e temporalidade homogênea do imperativo categórico. Já que as situações históricas não são idênticas umas às outras, nada pode ser categórico a priori. Apesar de a força da lei ligar-se a sua aplicabilidade universal a qualquer situar concreta, seu fundamento clássico na moralidade do imperativo categórico de Kant baseia-se em uma universalização acrônica, que a abstrai de situações concretas e, portanto, sem recorrência. Para Benjamin, então, o valor universal de uma instrução ética não pode confundir-se com a universalizar de julgamentos, princípios ou imperativos.

Tal discussão, no entanto, pode ser facilitada com a formulação alternativa dada por Kant a seu imperativo categórico, ao afirmar que o princípio moral essencial denota-se como "agir de modo a encarar a humanidade, própria ou alheia, sempre concomitantemente como fim, e nunca apenas como meio" (KANT, 2003, p. 116, tradução nossa). Para realizar a equivalência entre as duas formulações, é necessário pontuar que Kant indica ser o humano superior a qualquer coisa, por dois motivos: podem dar valor a coisas, de acordo com a utilidade que estas tem para seus objetivos - portanto, meios para seus fins - e por serem dotados de dignidade, seu valor intrínseco, que decorre da racionalidade.

A concepção estóica de Kant sobre a pessoalidade como razão é fortemente criticada por Martha Nussbaum, que aponta que tal correlação deixará com status subumano as pessoas com deficiência ou que tenham impedimentos mentais - mesmo os adquiridos com o envelhecimento. Assim, teríamos a esdrúxula situação de humanidade variável ao longo da vida, com a total incapacidade do nascimento, o início da aquisição da razão com o desenvolvimento infantil, a capacidade relativa pubescente, a racionalidade plena - e portanto, humanidade - do período adulto, e a nova perda do valor humano com eventual interdição 
senil. Nussbaum, portanto, considera "primário o valor das oportunidades das pessoas de viverem boas vidas, e a explicação da justificação política como posterior à explicação do que coloca as vidas em acordo com a dignidade humana possível” (NUSSBAUM, 2013, p. 190), para que cada pessoa possa efetivamente ser um fim em si mesmo. Logo, o dever de solidariedade - melhor que a fraternidade, pois tem caráter político - faz com que se deva promover os fins alheios o máximo possível, para que haja harmonia positiva - e não meramente negativa - com a humanidade como um fim em si mesmo (KANT, 2003, p. 118). Assim, não se pode manipular as pessoas, ou usá-las para alcançar fins individuais, por mais justificáveis que esses sejam. Deve-se possibilitar a ação humana de forma livre e autônoma, para que os objetivos de um se tornem voluntariamente os fins dos demais, que o fizeram através de escolhas informadas.

Ao colocar o homem como começo e fim de tudo, Kant já introduz conteúdo a seu imperativo. No entanto, se o ser humano é fim em si mesmo, não poderá ser instrumento para outro. Assim, as pessoas não podem servir à finalidade da empresa. Como, então, entender a ficção da pessoa jurídica? Apesar de as sociedades apresentarem distinta personalidade jurídica e poderem ser responsabilização por seu modo de agir - independente das pessoas envolvidas na companhia - qualquer empresa de deve ser entendida como empreendimento social, ou seja, entidades cuja existência e decisões somente podem ser justificadas se servirem a fins públicos ou sociais - sendo este um dos topos retóricos do Direito. Assim, para garantir felicidade social, é preciso cuidado com os meios, pois estes poderão ser fins para outros - e é este o caso das empresas. Ainda, sendo a empresa uma propriedade, esta deve se submeter à humanidade, por ser desta criação histórica - assim como o Estado, como indicado por Engels (1984) - e não essencial para a existência da sociedade. Desta forma, reforçando a necessidade de manter a humanidade como parâmetro, Douzinas pondera:

\footnotetext{
"Se abandonarmos o essencialismo da humanidade, os direitos humanos tornam -se contratos altamente artificiais, um acidente histórico do intelecto europeu e da história política. (...) A humanidade dos direitos humanos não é um significante vazio; ela carrega um enorme capital simbólico, um excesso resultante de valores e dignidade construído por revoluções e declarações e aumentado por cada nova luta que adota a retórica de direitos humanos. Tal excesso simbólico transforma o 'humano' em algo que lutas políticas sociais e jurídicas querem como aliado, e explica a importância de campanhas políticas." (DOUZINAS, 2007, p. 3/4)
}

De acordo com a ordem constitucional brasileira, a propriedade privada deve cumprir a sua função social. Para José Afonso da Silva (2006), a função social da propriedade não se confunde com seus sistemas de limitação, que tratam do exercício do direito do proprietário. A função social da propriedade privada visa a garantir a utilização produtiva dos bens de produção, proporcionando crescimento econômico e produção de riquezas na forma de um 
bem estar coletivo. Por sua vez, Celso Ribeiro Bastos (2010) indica que a finalidade da função social da propriedade é recolocar a propriedade na sua trilha normal, mesmo utilizando medidas de grande gravidade jurídica.

Agregando essas duas ideias, entende-se a função social da propriedade como poderdever (COMPARATO, 1986) de o proprietário compatibilizar a fruição individual do bem com o interesse coletivo, vinculando-o a certa finalidade social, evitando, pois, o abuso de propriedade. Eros Roberto Grau acrescenta que o princípio da função social é pressuposto necessário da propriedade privada e, segundo ele, sua ideia é de vínculo que atribui à propriedade um conteúdo específico que a conduz a um novo conceito. $\mathrm{O}$ autor continua:

O princípio da função social da propriedade ganha substancialidade precisamente quando aplicado à propriedade dos bens de produção, ou seja, na disciplina jurídica da propriedade de tais bens, implementada sob o compromisso com a sua destinação. A propriedade sobre a qual os efeitos do princípio são refletidos com maior grau de intensidade é justamente a propriedade, em dinamismo, dos bens de produção. Na verdade, ao nos referirmos à função social dos bens de produção em dinamismo, estamos a aludir à função social da empresa. (GRAU, 2012, p. 238) .

Aplica-se, portanto, por previsão constitucional indireta, a função social à empresa. No entanto, o seu significado depende da ideologia econômica utilizada. Internacionalmente, há três correntes principais que discutem qual seria a finalidade da empresa. A primeira, denominada produtivismo, assume a "postura tradicional", baseada na decisão da Suprema Corte de Michigan em Dodge v. Ford Motor Company, 204 Mich. 459, 170 N.W. 668 (1919). Para esse grupo, a missão da empresa é meramente econômica, sendo sua única função gerar lucros e dividendos para os acionistas - stockholders. O case apresentado, inclusive, julgou que os acionistas podem impedir que a empresa patrocine programas sociais filantrópicos, diminuindo o repasse dos lucros. Por isso, a maior parte da literatura considera que este modelo não comporta responsabilidade social, já que esta causaria redução de dividendos. Outros, porém, relatam que o produtivismo é a essência da responsabilidade social, ao estimular a maximização de seus objetivos produtivos, dentro dos ditames da lei. Comportamento diverso significaria que as empresas seriam irresponsáveis, ao desperdiçarem recursos sociais produtivos.

Para Milton Friedman (2002), expoente desta corrente, a maximização dos lucros é o objetivo das empresas em economias de mercados altamente competitivos. Desta forma, as ações dos executivos devem sempre se voltar ao lucro, de forma a melhor remunerar os 
acionistas. Por isso, investimentos corporativos na área social, para qualquer tipo de público interno ou externo, empregados ou a sociedade - lesam os acionistas, ao diminuir seus ganhos. Ao proceder com responsabilidade social, a empresa se autotributa, podendo ser processada. Desta forma, somente as organizações monopolistas, devido ao domínio completo do mercado, poderiam desenvolver programas sociais, pois conseguiriam manter seus lucros elevados, transferindo os gastos para o consumidor.

Em posição diametralmente oposta, a segunda corrente, filiada a uma nova ordem social, considera que o benefício social de uma empresa deve estar acima do benefício econômico. Para tanto, a propriedade privada não existe e os benefícios econômicos são compartilhados.

O terceiro grupo assume posição intermediária e recebe cada vez mais adeptos. Os progressistas sustentam basicamente que o lucro é legítimo e justo, mas isso não tira a exigência de uma postura social. Keith Davis (1975) a embasa em cinco pontos principais. Parte-se da ideia de que a responsabilidade social emerge do poder social. Devido a suas consequências sociais, relacionadas ao sistema social global, as decisões empresariais não podem se basear unicamente em fatores econômicos. A tomada de decisão, mesmo gerencial, deve buscar ações que também protejam os interesses da sociedade, pois, para desempenhar sua missão, as empresas precisam de grande volume de recursos da sociedade: logo, em contrapartida, elas devem utilizar tais recursos em favor dessa sociedade. O autor também afirma que ignorar a responsabilidade advinda de seu poder social é ameaçar a empresa, já que, em longo prazo, quem não usa o poder de modo considerado responsável pela sociedade tende a perdê-lo.

Assim, o quinto e último passo conclui que, apesar de as empresas não terem responsabilidade primária na solução de problemas sociais, devem prestar assistência à solução, na medida de suas possibilidades. Tais instituições, como qualquer cidadão, será beneficiada por uma sociedade melhor, logo deve reconhecer os problemas sociais e contribuir ativamente para saná-los.

A empresa, ao reunir enorme capacidade de influência perante a coletividade, não pode ser tratada apenas como uma produtora de rendas, mas também como um poder. Tal capacidade não traz somente direitos, mas também obrigações. Dessa forma, deve ser exigida da companhia uma proporcional - e correspondente - responsabilidade social.

Jussara Suzi Assis Borges Nasser Ferreira (2005) identifica, como princípios específicos da função social da empresa, o princípio da dignidade empresarial, o princípio da 
moralidade empresarial e o princípio da boa-fé empresarial. Seriam, portanto, funções sociais da empresa o desenvolvimento regular de suas atividades, observando a legislação e mandamentos constitucionais; o dever de atender aos interesses coletivos de todos os envolvidos na rede de produção e circulação de riquezas; a adoção de políticas sociais, econômicas, éticas, abrangendo preços justos e concorrência leal; gerar empregos; recolher tributos e agir de acordo com os usos e costumes sociais.

Constitucionalmente, os princípios informadores da ordem econômica dirigem as atividades empresariais. A livre iniciativa, portanto, é limitada, através do controle do abuso do poder econômico, da proteção ao direito do consumidor e da função social. Isto não significa, no entanto, que a empresa deve deixar de buscar lucros - já que esta é, como visto, sua função primordial. Tal limitação imposta pela função social não pulveriza a liberdade do empresário e nem transforma a empresa em mera provedora de fins sociais - até porque isso ofenderia a dignidade dos empresários e seria violação à livre iniciativa. A função social não transmuda a sociedade empresária em órgão público: sua finalidade é garantir a busca do bem social no exercício da atividade econômica. Neste sentido, vale citar Raquel Sztajn: A racionalidade dos agentes, um dos postulados econômicos, que leva à procura da maximização de utilidades, e a eficiência alocativa, segundo essa visão, vão ao encontro da ideia de solidariedade e geração de bem-estar coletivo. (SZTAJN, 2005, p. 76)

Por isso, questiona-se: a responsabilidade social é meio ou fim em si mesma? Inevitavelmente, a maximização dos lucros é o fim individual dos acionistas, mas, para a coletividade, é meio para alcançar o bem-estar. Compatibilizar a busca pelo lucro com o cumprimento das obrigações sociais mais amplas que o mero fornecimento de bens e serviços à comunidade não é ideia exclusiva de interpretações integrativas da CF/88: a Lei das S/A traz expressamente em seu art. 116 que a empresa deve prezar pelo cumprimento de deveres e responsabilidades não apenas para com os acionistas, mas também com seus trabalhadores e comunidade. Na mesma linha, o art. 154 da mesma lei revela que a gestão deve se preocupar com a obrigação social da empresa, que buscara seus interesses satisfazendo as exigências do bem público e da função social da empresa. Finalmente, o parágrafo quarto do mesmo artigo prevê responsabilidades sociais da empresa, ao permitir a prática de atos gratuitos em benefício dos trabalhadores ou da comunidade de que participe a empresa. Refuta-se a fundamentação de Dodge v. Ford Motor Company no Brasil, por previsão legal de possibilitar praticas de responsabilidade social. Este artigo evidencia o caráter conciliador da Lei das S/A, ao harmonizar a obrigação de buscar o lucro para acionista - "lograr os fins e no interesse da 
companhia", no caput - com a difusão da CSR - "tendo em vista suas responsabilidades sociais", no $\S 4^{\circ}$.

Assim, o Brasil tempera o direito à propriedade - inclusive a empresarial - com o cumprimento de sua função social, devendo, portanto, ser meio para realização da sociedade. Logo, a próxima seção observará como - ou se - as empresas se prestam a tal desenvolvimento da dignidade das pessoas, analisando sua vinculação aos direitos humanos.

\section{Empresas e Direitos Humanos: mera obrigação de respeitar?}

As empresas podem ter impactos - diretos ou indiretos - em praticamente todo o espectro de direitos humanos. Até direitos como o de julgamento imparcial, que é claramente direcionado aos Estados, pode ser adversamente afetado se, por exemplo, obstruir provas ou interferir com as testemunhas. Cada atividade empresarial terá um grupo de direitos que lhes exigirá mais atenção, pelas circunstâncias de mercado ou pela característica da industria correlata, mas não é possível limitar a aplicação da responsabilidade em respeitar direitos humanos através de uma correlação entre subgrupo de direitos e atividade explorada, pela característica complementar dos direitos humanos.

As vantagens usualmente listadas para que as empresas adotem políticas de direitos humanos são: proteção da imagem e reputação perante os consumidores; redução do risco de interrupções por greves, protestos e boicotes; aumento da atratividade para talentos em seu quadro de funcionários - atual e futuro; e, finalmente, em alguns casos, por ser a coisa certa a fazer. No entanto, essas ideias ainda tendem a ser vistas como novas, ou como frivolidades passageiras do mercado. Muitos tomadores de decisão corporativos não veem necessidade em ajustar suas políticas, se isso afetar os lucros em curto prazo; para os seguidores de Friedman, os programas de direitos humanos ferem a obrigação de maximização de lucro. Por outro lado, pode-se indicar duas situações atuais que forçam a atenção corporativa a se voltar aos direitos humanos: primeiro, a decisão de alguns governos - como Países Baixos e Reino Unido - de condicionar garantias de crédito para a exportação com os impactos potenciais em direitos humanos do projeto; e finalmente, os complexos cálculos que fatoram o cumprimento dos direitos humanos em ações e níveis creditícios, particularmente em fundos que anunciam dimensão ética, como os fundos de pensão do Reino Unido, que são legalmente obrigados a revelar em que extensão questões éticas, sociais e ambientais são consideradas para selecionar e reter investimentos. 
As políticas empresariais sobre direitos humanos estão em sua infância, e o escrutínio governamental de tais ações, em fase embrionária, mas já existem discussões internacionais acaloradas sobre o tema. Durante a primeira fase de negociações na ONU sobre a relação entre Direitos Humanos e corporações multinacionais, a partir de 1970, buscou-se entender quais seriam os impactos dessas empresas no processo de desenvolvimento especialmente em países em desenvolvimento - e as relações internacionais. Para tanto, seria formulado um código de conduta que trataria tanto das responsabilidades - ligadas às atividades das empresas - quanto aos seus direitos - o tratamento que receberiam dos Estados, o que impediu o consenso entre países desenvolvidos e em desenvolvimento, pois "os Estados mais poderosos, por meio do discurso dos Direitos Humanos, fizeram das suas prioridades a preocupação principal dos outros" (LEWIS, 1988, p. 89). Abandonado no início dos anos 1990, o código proposto indicava que as multinacionais deveriam respeitar direitos humanos, direitos fundamentais e liberdades fundamentais nos países em que operassem.

$\mathrm{Na}$ segunda fase de discussões, foi elaborado um documento específico sobre direitos humanos e empresas, o Global Compact, criticado por conter meramente obrigações morais voluntárias para as empresas. O grupo de trabalho visou a catalogar as responsabilidades em direitos humanos das corporações, que participaram ativamente do processo, junto com ONGs, influenciando na feitura das normas e revelando a importância de atores não estatais para o direito internacional.

A terceira fase iniciou-se em 2005, com a indicação Professor John Ruggie como Representante Especial do Secretário Geral da ONU para Direitos Humanos e Corporações Transnacionais e Outras Empresas. O grupo de trabalho criado realizou consultas com diversos stakeholders, como as empresas, ONGs e acadêmicos - exceto as vítimas de abusos de direitos humanos -, utilizando uma abordagem bottom-up na criação das normas. No entanto, a força da participação empresarial fez com que os padrões de direitos humanos resultantes fossem estreitos e com baixa imperatividade - já que seriam as próprias corporações que os cumpririam. Essa estratégia no entanto, foi crucial para que o grupo de trabalho atingisse consenso e garantisse o apoio efetivo da ONU: para tanto, precisou se afastar de discussões controversas, tanto para os Estados - já que o relativismo minara o consenso na primeira fase - quanto para empresas. Não se usou a redação normativa kelseniana, com comando primário e sanção secundária: os líderes das empresas foram guiados, através de um conjunto de compromissos mÍnimos, a aceitar a ideia de que o mercado tem responsabilidade de respeitar os direitos humanos, justamente por terem podido 
determinar que responsabilidade seria essa: é persuasivamente eficaz apresentar os próprios fins como fins gerais. Porém, como indicado por Bobbio, "o problema fundamental em relação aos direitos do homem, hoje, não é tanto o de justificá-los, mas o de protegê-los. Trata-se de um problema não filosófico, mas político" (2004, p. 43).

As diretrizes Ruggie utilizaram a metodologia denominada pragmatismo principiológico. Bilchitz e Deva (2013, p. 12) indicam que o discurso de direitos humanos não se afasta do pragmatismo, como evidenciado no processo de efetivação do Pacto Internacional sobre Direitos Econômicos, Sociais e Culturais - PIDESC: é pragmático reconhecer que a realização imediata dos direitos socioeconômicos requer um certo grau de recursos e capacidades que alguns estados podem não ter. Assim, desenvolvem-se um centro mínimo de obrigações para lidar com necessidades urgentes no curto prazo, postergando a realização plena e adequada daqueles direitos no futuro, quando for possível.

No entanto, tal pragmatismo no PIDESC é de diferente natureza, pois só é visível na realizado dos direitos humanos. Em sua definição, os direitos humanos tendem a ser principiológicos, programáticos - por isso sua denominação como metadireitos. Ruggie, no entanto, considerou o pragmatismo como base para todo o seu trabalho - inclusive na fase de elaboração das normas. Assim, as responsabilidades das empresas para os direitos humanos foram normatizadas em um patamar muito baixo. Não há obrigações imperativas: há meramente o dever se respeitar os direitos humanos, o que foi definido como obrigação negativa de feri-los, e não positivamente ajudar em sua realização. Apesar de a empresa ter que adotar certas medidas, como criação de códigos internos de conduta, instituição de procedimentos para due diligence e procedimentos de reparação - conforme o princípio diretivo 15 -, o foco permanece em abster-se de causar o dano.

As normatizações oriundas desta mais recente fase, apesar das críticas contundentes feitas por consultores internacionais, prestam-se à finalidade de gerar mínimas prescrições sobre o tema, retirando da bússola ética a total decisão corporativa para respeito aos direitos humanos. As ideologias éticas da pós modernidade são formas de irrealismo moral sob a premissa da falácia anti-naturalista, que nega qualquer possível verdade moral - não há deverser decorrente do ser -, sendo, portanto, perspectivas éticas não-cognitivistas - com exceção do descritivismo. (HARTWIG, 2007, p. 182). O prescritivismo kantiano indica que as regras morais são universalmente vinculantes, não importando o contexto particular. $\mathrm{O}$ prescritivismo em sua versão moderna, de acordo com a teoria de R. M. Hare (1996) em oposição ao emotivismo indica, como o realismo crítico, que os julgamentos morais são 
imperativamente prescritivistas e universalizáveis: dizendo-se que alguém deve agir de determinada forma, compromete-se ao mesmo em circunstâncias similares. No entanto, contrariamente ao realismo crítico, essa teoria aceita a dicotomia descritivista avaliativa, indicando que a adoção de um princípio ético é uma questão de comprometimento pessoal, logo aproximando-se do emotivismo. Hare indica ser diferente dizer a alguém o que ele deve fazer e efetivamente conseguir que ele o faça, se ele não estiver disposto àquilo. Assim, o imperativo seria puramente prescritivo, mas, em um segundo momento, analisa-se se a linguagem é suficientemente persuasiva - e, para tanto, pode-se usar de emotivismo ou de lógica descritiva - para levar o agente a realizar a ação. O descritivismo é cognitivista, mas em oposição não dialética ao prescritivismo, indicando que o significado de qualquer regra moral é puramente factual, ou seja, determinada pelas condições reais. Reduz-se, então, os valores a fatos, o possível para o existente, impossibilitando falar-se de um descritivismo metafísico, como argumenta Hume. A descrição deve estar relacionada a questões reais, e o desejo em cumprirão não faz parte de uma afirmação puramente factual. Assim, Hume indica que não se pode passar de afirmações ser/não ser para proposições regidas pelo dever ser. Assim, não se pode traçar uma relato exclusivamente lógico entre um julgamento moral e a motivação para segui-lo.

Apesar das diferenças, tanto o descritivismo quanto o prescritivismo são cúmplices tácitos na manutenção das relações de poder existentes, as quais são discursivamente moralizadas por tais correntes (HARTWIG, 2007, p. 183). E uma das relações de poder mantidas por essa simbiose é o Direito, composto por duas posições: como ele é de fato - ser, descritivo - e, através de críticas, indicar como ele deveria ser - prescrição. Tais avaliações dependeriam de atitudes, que não fazem parte da definição essencial do Direito, possibilitando o positivismo monista da Teoria Pura do Direito. O ser e o dever ser são distintos, em novel ontológico e epistemológico, como indicado por Rabenhorst (2005) em análise sobre Kelsen: ontologicamente, a norma jurídica é um dever ser, prescritivo, por ser ela a significação de um ato de vontade que a instaura - este, sim, o ser. "Neste sentido, as normas jurídicas são esquemas de interpretação', e a tarefa da ciência do direito consiste precisamente em descrever tais esquemas" (ibid, p. 124). Em termos epistemológicos, a Teoria Pura do Direito indica ser este uma ciência normativa, descritiva nas normas, que não se deixam apreender com causalidade.

Assim, descrição e prescrição fazem com que o Direito possa ser interpretado, respectivamente, como sistema de normas jurídicas e a disciplina que descreve tal sistema. A 
prescrição normativa, no entanto, não significa que ela não realize ação. A linguagem prescrita é performativa, pois orienta condutas, o que é condizente com a teoria de J. L. Austin (1990) de que a linguagem não é mera descrição, mas forma de agir no mundo. E, voltando a Hare, essa ação afeta tanto o locutor - que efetivamente a realiza, proferindo palavras que visam a orientar a conduta do outro - quanto o interlocutor, potencialmente (ARAUJO E HENRIQUES, 2013, p. 227). Volta-se à importância retórica dos direitos humanos.

Os Estados adotam textos internacionais que se dirigem diretamente às corporações e que especificamente indicam o respeito dos direitos humanos por qualquer entidade de mercado. Os indivíduos foram reconhecidos como detentores de direitos internacionais quando os tribunais internacionais exerceram jurisdição sobre tais direitos e deveres. No entanto, apesar de serem pouquíssimas as situações em que uma corporação pode ser chamada a responder perante um tribunal internacional, como no Tribunal Internacional sobre Direito do Mar, a judicialização não é requisito essencial para que as corporações tenham deveres internacionais. As obrigações internacionais podem existir independentemente de uma instituição internacional que a processe - a qual pode ser criadas posteriormente, e julgará de acordo com a obrigação existente à época, mesmo se decorrente de dever não escrito ou reconhecido pelo Estado nacional. Assim, é sensato falar-se no filtro jurisdicional, que retrata a separação entre obrigações de direito internacional e a jurisdição internacional para o processo. Assim, a ausência de tribunais internacionais com competência para o julgamento das corporações não significa que estas não possam quebrar prescrições de direito internacional. A violação de direitos humanos por empresas pode ocorrer de três formas, de acordo com o guia interpretativo dos princípios Ruggie (2012): a corporação pode causar o impacto, através de suas atividades; pode contribuir para o impacto, através de suas atividades - seja diretamente ou por meio de outra entidade; e pode simplesmente encontrar-se envolvida no impacto causado por entidade com a qual tenha relações de negócio e com ela se ligue por suas operações, produtos e serviços. Causando ou contribuindo para a violação, Ruggie indica que a empresa terá dever de cessar a ação danosa e remediá-la. No entanto, com o mero envolvimento, a empresa não poderá ser responsabilizada solidariamente, tendo apenas obrigação de utilizar a sua influencia para encorajar a entidade causadora para que esta cesse ou diminua o dano.

Finalmente, o princípio 13 reforça que será obrigação das corporações o respeito aos direitos humanos, significando evitar causar ou contribuir para impactos, e, caso estes 
ocorram, mitigá-los, se diretamente ligados às suas atividades. É patente que Ruggie descarta deveres de promoção de direitos humanos - os quais ficam relegados à voluntariedade e filantropia corporativa. Assim, a promoção dos direitos humanos continuaria sendo obrigação exclusiva dos Estados. Observa-se, então, que "há uma séria lacuna em nível internacional com implicações significantes, devido ao potencial papel das empresas na solução de desafios como sustentabilidade ambiental e pobreza global.” (BILCHITZ, 2013, p. 108)

Indicar, pois, que a empresa cumprirá sua função social apenas com deveres negativos sobre direitos humanos, faz com que as diretrizes Ruggie demonstrem entendimento limitado de legitimidade democrática, "além de perpetuar a contraproducente ideia competitiva de obrigações do Estado e de mercado, em vez de uma visão colaborativa, com maior probabilidade de indicar a realização dos direitos humanos.” (BILCHITZ, p. 108)

Deste modo, a próxima seção discutirá qual o papel da promoção dos direitos humanos voluntariamente pelas empresas, a Responsabilidade Social Corporativa - CSR -, e se esta consegue efetivamente contribuir para o desenvolvimento.

\section{Entre a ética e o lucro: as faces da responsabilidade social corporativa}

Considerando a Responsabilidade Social Corporativa - CSR - como uma campanha humanitária, o humanismo trazido por essa noção é um significante aberto (DOUZINAS, 2007, p.4). Assim, o "humano" é definido de acordo com as regras e necessidades da acumulação do capital. Douzinas acrescenta que "os direitos humanos não pertencem aos homens e não seguem as imposições da humanidade: eles constroem humanos" (2007, p.4 tradução nossa). Nesse contexto, ele identifica três máscaras humanas: a vítima, o malfeitor e o salvador moral - que constrói os anteriores. Culpando o malfeitor por violações de direitos humanos, de normas internacionais ou regras democráticas, o salvador cria sua legitimidade para atacar, incorporando um discurso moral. A vítima é o construto colateral do malfeitor, sendo "aquela cuja dignidade e valor foram violados" pelo mal, que feriu direitos humanos. O cenário da vítima e do malfeitor é o mesmo: ambos vivem em estados subdesenvolvidos. Finalmente, o salvador define a crise na região em que ele já construira o malfeitor e a vítima - que são os seus outros. Colocando-se em uma posição diferente, de não violador de direitos humanos, o salvador com intenções morais vem ao resgate da vítima do malfeitor, e legitima seus atos - mesmo que seja uma intervenção militar. O mais forte, como salvador moral, reproduz seu poder repetidamente. 
Similarmente, a responsabilidade social corporativa - ou a ética do negocio - ganha força quando há crise sobre considerações éticas no mercado global. Tal crise, antes invisível, surge quando campanhas anti-globalização e anti-corporativismo começaram a ameaçar a necessária circulação do capital. "Sugere-se que as pessoas não confiam mais no mercado, que imagens negativas das empresas são comuns na mídia, que a hiper-competição faz com que os trabalhadores percorrem não importa os custos" (PARKER, 2003, p. 199 - tradução nossa). Quando a nomenclatura de Douzinas é aplicada à CSR, a vítima e o salvador são facilmente identificáveis: a vítima é construída como pessoa, comunidade ou recurso natural afetado por consequências ruins da globalização, que é usada como conceito neutro. A vítima pode ser uma floresta explorada, uma cidade-fantasma decorrente do declínio da exploração petrolífera, uma criança que não tem acesso a educação básica ou um trabalhador que não consegue se manter com o salário minguado de sua atividade informal. O salvador, por sua vez, é incorporado pelas instituições capitalistas, particularmente as corporações internacionais, que fornecem melhores condições de trabalho e de vida para os necessitados, que doam medicações, que fornecem bolsas para estudantes, que movimentam economias e que preservam florestas para as gerações futuras. No entanto, a ideologia capitalista é perspicaz em esconder o malfeitor: devido à ilusão que cria, o malfeitor não é facilmente identificável no contexto da CSR - portanto, no contexto do capitalismo global simplesmente por ser o próprio modo de produção em tela. Utilizando significantes abertos, como globalização, subdesenvolvimento, falta de modernização, ineficiência ou corrupção, o capitalismo intencionalmente esconde o malfeitor, impossibilitando a identificação de suas instituições como as causas das crises. Assim, a sociedade se torna palco de um libreto em que as instituições capitalistas interpretam os salvadores das vítimas ao redor do mundo, escondendo seu lado vilão - justamente o fator que define o livre-mercado como o salvador e a sociedade como a vítima.

O discurso capitalista tende a se autojustificar e criar uma imagem essencialmente benéfica ao bem comum. Como um dos atores mais poderosos do capitalismo e que arrasta as discussões éticas na arena global, as corporações multinacionais não ficam atrás no processo de estetização - ao contrário, a imagem corporativa dessa ética de mercado gera o conceito de responsabilidade social corporativa, que tende a extrapolar as atividades empresariais, ligando-se às arenas político-econômicas globais.

Friedman, economista neoliberal e um dos mais famosos defensores da economia capitalista, é criticado por colegas neoliberais que acreditam que a fase atual do capitalismo 
precisa de uma imagem ética para sobreviver, Com a era da globalização, essas críticas aumentaram: seus argumentos científicos incluem parâmetros éticos individualistas e utilitaristas, que não conseguem ligar economia e sociedade, colocando maior relevaria em benefícios de curto prazo. A teoria stakeholder pode ser considerada como uma resposta ao parâmetro neliberal de Friedman, permitindo que o mercado estabeleça relações com outros atores, além dos acionistas, desde que isso seja benéfico, ou meramente lucrativo, para a corporação. É relevante apontar, ainda, que essas duas correntes apresentam análises internas à empresa. A perspectiva de responsabilidade corporativa em nível global, segundo a qual as corporações devem ter agenda que considere os interesses da sociedade e de contribuições mais abrangentes para o desenvolvimento econômico e sustentável, incluindo o desenvolvimento de países em desenvolvimento, permite um maior aprofundamento da análise, tornando-se o predominante em organizações internacionais. A responsabilidade social corporativa sob qualquer das três correntes, no entanto, não tem qualquer problema com as relações capitalistas, meramente visando a protege-las e melhorá-las. Assim, por essas perspectivas, não há d/vidas de que o mercado tem maior poder que qualquer outra instituição econômica ou social, e a intervenção do domínio privado no social seria legítima e inquestionável.

Por outro lado, posições críticas não se sentem confortáveis com as relações capitalistas e o crescimento da influencia do mercado na sociedade. Assim, questionam-se os discursos normativos das instituições capitalistas. Banerjee indica que o refinamento das relações mercado e sociedade promovido pela CSR em nenhum momento colocam em xeque as questões fundamentais da agenda neoliberal, servindo apenas para aumentar a legitimidade das estruturas existentes (BANERJEE, 2007, p. 155). A CSR, então, não é vista como um discurso ético, mas sim como um meio para legitimar a dominação das corporações. $\mathrm{O}$ conceito, então, não passaria de um instrumento ideológico para aumentar o poder das corporações, não sendo capaz de promover mudanças sociais relevantes. No entanto, sua contribuição teórica não consegue avançar além da crítica da situação atual. Banerjee indica a necessidade de novas teorias sobre a natureza e papel das corporações, através da adoção de uma nova ontologia que considere a empresa como um agente para mudança social positiva (2007, p. 143). Similarmente, Bakan indica a necessidade de criar-se corporações com fins sociais, o que geraria a necessidade de uma mudança econômica, com maior intervenção estatal (BAKAN, 2004, p.160). Newell também indica que, para controlar o mercado, uma regulação que não seja um fim em si mesmo, mas meio para atingir fins socioambientais mais 
abrangentes deve ser considerada, em vez da manutenção do laissez-faire (NEWELL, p. 2008, 1076).

No entanto, quaisquer dessas perspectivas críticas deixam de questionar os problemas sistemáticos do capitalismo. É contraditório analisar a CSR como uma tentativa consciente de modificar o sistema de livre mercado enquanto ainda se buscam melhor formas de implementa-la. A análise termina se fechando apenas na formação atual das empresas, como visto. No entanto, o sistema capitalista e suas instituições deve ser analisado como um todo, para gerar um ponto nodal de exame do livre mercado, possibilitando avançar em relação aos meros resultados situacionais e criticar as corporações per se. Ainda, a literatura crítica mantém a distinção entre mercado e sociedade, trazida pela teoria administrativa, como dois centros independentes e igualmente poderosos, retirando do escrutínio como as relações econômicas podem determinar as demais estruturas sociais das sociedades capitalistas.

Nenhuma mudança que emane da esfera econômica será suficiente para gerar efetivas mudanças sociais, enquanto a economia não esteja subordinada ao controle consciente dos indivíduos (JAPPE, 1999, p. 4). No entanto, o espetáculo atual, em sentido debordiano, pode revelar uma mudança do sistema econômico existente, pois está vindo de fora desse sistema. A dominação de imagens no espetáculo perverte a realidade de tal forma que uma mudança realizada para manter a estrutura econômica pareça um ato para mudança da estrutura social. Em outras palavras, o discurso sobre mudança social é uma ilusão do capitalismo hegemônico que serve para legitimar a exploração econômica. No entanto, isso não significa que a dominação não possa ser quebrada.

Desta forma, a CSR contribui com a separar da sociedade, mas se apresenta como um instrumento de unificação, através de suas tentativas de conectar sociedade e economia (DEBORD, 1977, tese 3). No entanto, o estabelecimento de tal elo visaria a beneficiar a economia capitalista, e não os trabalhadores, que permanecem sem unidade de classe na linguagem da CSR. Os trabalhadores são comparados entre si como se não estivessem na mesma situação, escondendo o real conflito e impedindo a luta de classes. Ainda, os valores humanitários da CSR claramente se fazem presentes com a finalidade de prevenir interrupção na circular de commodities e do capital. Sendo a circulação essencial para o modo de produção capitalista, os valores humanitários, como o discurso sobre direitos humanos, direitos trabalhistas, direitos da mulher e princípios igualizarias são usados como mecanismos para atingir estratégias de negócio mais efetivas e lucrativas. Tais valores se veem no centro do processo de comoditização, cujo objetivo principal é a acumulação. Por estes fatores, 
AKBAS (2012) indica ser "possível entender a CSR como fenômeno materialístico em sentido econômico, em vez de moral, como o conceito é apresentado" (2012, p. 48 - tradução nossa).

Ativistas preocupados com as consequências socialmente danosas das corporações propuseram uma distinção entre responsabilidade corporativa e accountability corporativa. A responsabilidade corporativa refere-se a qualquer tentativa de fazer com que as empresas se comportem responsavelmente de forma voluntária, devido a considerações éticas ou utilitaristas. Essa corrente é adotada em arenas internacionais, como o Global Compact da ONU e pela Câmara Internacional de Comércio. A accountability corporativa, por sua vez, refere-se a requisitar que as corporações se comportem de acordo com normas sociais ou encarem as consequências. A preferência corporativa por iniciativas voluntárias, em oposição a obrigações legalmente positivadas, atualmente é criticada pelas mesmas organizações internacionais que antes encorajaram tal voluntariedade na CSR: organizações não governamentais, como a Christian Aid, declaram atualmente que os governos devem retomar suas obrigações, pois a autogovernança das corporações multinacionais sobre direitos humanos é extremamente deficitária. Assim, a Christian Aid ressalta ser necessário das “dentes" para as obrigações éticas das empresas, transformando a CSR - que não consegue nem irá causar mudanças profundas - em accountability social corporativa, para garantir que as companhias sejam legalmente obrigadas a atingir os padrões internacionais. "Trabalhos internacionais futuros devem buscar uma concepção mais adequada de obrigações corporativas, fundadas nas bases normativo-principiológicas dos direitos humanos" (BILCHITZ, 2013, p. 108)

No entanto, a ênfase crescente nos direitos humanos em relação ao investimento ético pode explicar em parte a resistência do setor corporativo em apoiar novas iniciativas que pudessem aumentar sua accountability legal. Assim, as obrigações das empresas sobre direitos humanos tendem a passar das prescrições frouxas de soft law para hard law com “dentes suficientes”. Para tanto, deverá ocorrer a retomada da regulação estatal para promover tal responsabilização corporativa. 


\section{CONSIDERAÇÕES FINAIS}

A adoção de medidas de responsabilidade social corporativa, apesar de não coercitiva, é benéfica para a atividade empresarial, por questões difusas, como endomarketing. No entanto, é relevante lembrar que empresas não se eximem de minorar ou, preferencialmente, anular - os impactos negativos de sua exploração, já que a Constituição de 1988 vinculou a atividade empresarial à promoção de sua função social. Essa função não se restringe ao lucro, objetivo maior da empresa - como defendido por Friedman mas também não o nega: deseja-se apenas que a atividade empresarial seja socialmente responsável, respeitando as obrigações legais e a comunidade em que se insere. Neste sentido, surge a responsabilidade social empresarial - da qual a cidadania corporativa é ramo político -, corrente gerencial adotada pelas empresas devido a motivações instrumentais, já que, empiricamente, gera benefícios para a companhia, aumentando o seu valor, mesmo indiretamente.

O fomento da responsabilidade social da empresa, no entanto, deve considerar suas consequências políticas: o aumento excessivo do poderio empresarial, ao tornar as companhias responsáveis pelo bem estar social, pode diminuir a confiança na democracia, já que o garantidor dos direitos individuais e humanos é o Estado, principalmente. Por outro lado, a sua adoção é forma de promover a função social da empresa, obrigação constitucional brasileira, mas os dois conceitos não se confundem: enquanto a responsabilidade social corporativa é de caráter gerencial e sua adoção segue lógica instrumental voltada ao lucro, a função social da empresa decorre do postulado da função social da propriedade, sendo norma de observância obrigatória e que apresenta limites à autonomia privada. Assim, deve este ser o objetivo dos programas, para que se possa falar de empresas com direitos humanos. 


\section{REFERÊNCIAS}

AKBAS, Eren. A sociological study of corporate social responsibility: a marxist perspective. Ancara: METU, 2012.

ARAUJO, Leandro Shigueo; HENRIQUES, Stefania Montes. A linguagem da moral: performatividade e prescritividade. In Acat Scientiarum. Human and Social Sciences. Maringá, v. 35, n. 2, p. 221-227, jul-dec, 2013.

AUSTIN, J. L. Quando dizer é fazer - palavras e ação. Porto Alegre: Artes Médicas, 1990.

BAKAN, Joel. The Corporation: The Pathological Pursuit of Profit and Power, New York: Free Press, 2004

BANERJEE, Subhabrata Bobby. Corporate Social Responsibility: The Good, the Bad, and the Ugly. Chetelham: Edward Elgar Publishing, 2007

BASTOS, Celso Ribeiro. Curso de direito constitucional positivo. São Paulo: Malheiros, 2010 BILCHITZ, David; DEVA, Surya. The human rights obligations of business: a critival framework for the future. In DEVA, S; BILCHITZ, D. (org.) Human Rights Obligations of Business: beyound the corporate responsibility to respect? Cambridge: Cambridge University Press, 2013

BOBBIO, Norberto. A era dos Direitos. Rio de Janeiro: Elsevier, 2004

BENJAMIN, Walter. O anjo da história. Belo Horizonte: Autêntica Editora, 2003.

CLAPHAM, Andrew. Human Rights Obligations of Non-State Actors. Oxford: Oxford University Press, 2006

COMPARATO, Fábio Konder. Função Social da Propriedade dos Bens de Produção. Revista De Direito Mercantil, Industrial, Economico e Financeiro, v. 63, p. 71-79, 1986.

DAVIS, Keith. Five Propositions for Social Responsibility. Business Horizons, 18(3): 19-24, June 1975.

DEBORD, Guy. Society of the Spectacle, 1977. Disponível em: http://www.marxists.org/reference/archive/debord/society.htm Acesso em 05 set 2015

Comments on the Society of Spectacle, 1988. Disponível em http://libcom.org/files/Comments\%20on\%20the\%20Society\%20of\%20the\%20Spectacle.pdf. Acesso em 05 ser 2015

Dodge v. Ford Motor Company, 204 Mich. 459, 170 N.W. 668 (1919)

DOUZINAS, Costas. The many faces of humanitarianism. In Parrhesia, n. 2, 2007, p. 1-28. . O fim dos direitos humanos. São Leopoldo: Unisinos, 2009.

ENGELS, Friedrich. A origem da Família, da propriedade privada e do Estado. Rio de Janeiro: Civilização Brasileira, 1984 
FRIEDMAN, Milton. Capitalism and freedom; Fortieth anniversary edition. Chicago and London: University of Chicago Press, 2002.

GRAU, Eros Roberto. A ordem econômica na constituição de 1988: interpretação e crítica. 11. ed. São Paulo: Malheiros, 2006.

HARE, R. M. A linguagem da moral. São Paulo: Martins Fontes, 1996. HARTWIG, Mervyn. Dictionary of Critical Realism. New York: Rutledge, 2007 JAPPE, Anselm. Guy Debord, University of California Press, 1999

JUDT, Tony. O mal ronda a terra: um tratado sobre as insatisfações do presente. Rio de Janeiro: Objetiva, 2011

KANT, Immanuel. Fundamentación para una metafisica de los costumbres. Madrid: Alianza Editorial, 2008

KELSEN, Hans. Qué es justicia? Barcelona: Editorial Ariel, 2008

LEWIS, Norman. Human rights, law and democracy in an unfree world. In EVANS, Tony (ed.), Human Rights Fifty Years on: A reapprasal. Manchester: Manchester University Press, 1988

NEWELL, Peter. "CSR and the Limits of Capital". In Development and Change, 39(6), pp. 1063-1078, 2008

NUSSBAUM, Martha C. Fronteiras da Justiça: Deficiência, Nacionalidade, Pertencimento à espécie. São Paulo: Editora WMF Martins Fontes, 2013.

PARKER, Martin. "Business, Ethics and Business Ethics: Critical Theory and Negative Dialectics" in Alvesson, Mats; Willmott, Hugh (eds) Studying Management Critically, SAGE Publications, 2003, pp.197-219

RABENHORST, Eduardo Ramalho. Ser e dever ser na teoria kelseniana do direito. in Revista Direito e Liberdade - ESMARN - Mossoró, v. 1, n.1, p. 119 -130, jul/dez 2005

RUGGIE, John Gerard (2002) "The Theory and Practice of Learning Networks: Corporate Social Responsibility and the Global Compact", JCC 5, pp. 27-36. Disponível em: http://demo10.wizzy.co.uk/content/pdfs/jcc05rugg.pdf Acesso em 09 set 2015

SILVA, José Afonso da. Curso de Direito Constitucional Positivo. 27a. edição - São Paulo:Malheiros, 2006

SZTAJN, Rachel; ZYLBERSZTAJN, Decio; AZEVEDO, Paulo Furquim. Economia dos contratos. In: ZYLBERSZTAJN, Decio e SZTAJN, Rachel. Direito \&Economia: análise econômica do Direito e das Organizações. Rio de Janeiro: Elsevier, 2005.

UN. The corporate responsibility to respect Human Rights: an interpretive guide. Geneva: United Nations, 2012 